\title{
Accuracy of milk ketone bodies from flow-injection analysis for the diagnosis of hyperketonemia in dairy cows
}

\author{
J. Denis-Robichaud, ${ }^{*}$ J. Dubuc, ${ }^{* 1}$ D. Lefebvre,† and L. DesCôteaux* \\ *Faculté de Médecine Vétérinaire, Université de Montréal, C.P. 5000, St-Hyacinthe, Quebec, J2S 7C6, Canada \\ †Valacta, Ste-Anne-de-Bellevue, Quebec, H9X 3R4, Canada
}

\begin{abstract}
The objectives of this study were (1) to determine the correlations between blood $\beta$-hydroxybutyrate (BHBA) and milk components [BHBA, acetone, fat, protein, and fat:protein (F:P) ratio], and (2) to establish optimal thresholds for milk components to predict hyperketonemia in dairy cows. Data on 163 cows from 37 herds were used in this cross-sectional study. Herds were visited once during the study period, and cows between 2 and $90 \mathrm{~d}$ in milk were blood sampled within $4 \mathrm{~h}$ of milk sampling for the Dairy Herd Improvement test. Blood BHBA concentrations were measured using a cow-side electronic meter, Precision Xtra, which was considered the gold standard test in this study. Milk BHBA and acetone concentrations were measured in Dairy Herd Improvement milk samples by flow-injection analysis; whereas, milk fat and protein were tested using Fourier transform infrared spectroscopy. Hyperketonemia was defined by a blood BHBA concentration $\geq 1.4 \mathrm{mmol} / \mathrm{L}$. The prevalence of hyperketonemia (based on blood BHBA values) in this study population was $21.0 \%$. Pearson correlation coefficients between blood BHBA and milk BHBA, acetone, fat, protein, and $\mathrm{F}: \mathrm{P}$ ratio were $0.89,0.73,0.21,0.04$, and 0.17 , respectively. Receiver operating characteristic curves were generated and thresholds for each individual milk component were determined based on the maximal sum of sensitivity and specificity. Optimal threshold values for hyperketonemia were milk BHBA $\geq 0.20 \mathrm{mmol} / \mathrm{L}$, acetone $\geq 0.08 \mathrm{mmol} / \mathrm{L}$, fat $\geq 4.2 \%$, and $\mathrm{F}: \mathrm{P}$ ratio $\geq 1.3$. Based on these thresholds, milk BHBA and acetone had greater sensitivity ( 84 and $87 \%$, respectively) and greater specificity (96 and 95\%, respectively) than the other milk components (fat, protein, and F:P). Series and parallel testing slightly improved the accuracy of milk BHBA and acetone values to predict hyperketonemia. A multivariable model that accounted for milk BHBA and milk acetone values simultaneously had the
\end{abstract}

Received March 1, 2013.

Accepted February 11, 2014.

${ }^{1}$ Corresponding author: jocelyn.dubuc@umontreal.ca highest accuracy of all tested models for predicting hyperketonemia. These results support that milk BHBA and milk acetone values from flow-injection analysis are accurate diagnostic tools for hyperketonemia in dairy cows and could potentially be used for herd-level hyperketonemia surveillance programs.

Key words: hyperketonemia, milk, flow-injection analysis, $\beta$-hydroxybutyrate

\section{INTRODUCTION}

Hyperketonemia is defined as an abnormally high concentration of circulating ketone bodies (Andersson and Emanuelsson, 1985) and is an indicator of excessive negative energy balance in transition dairy cows (Duffield et al., 2009). The gold standard for diagnosing hyperketonemia is the measurement of BHBA in serum or plasma (Duffield et al., 1998). A serum BHBA concentration of $1.4 \mathrm{mmol} / \mathrm{L}$ or greater during the first weeks postpartum is often used to define hyperketonemia and was shown to be associated with impaired subsequent health, production, and reproduction in dairy cows (LeBlanc et al., 2005; Duffield et al., 2009; Ospina et al., 2010).

Accurate and user-friendly tools that facilitate cowside measurement of BHBA concentrations are needed. Precision Xtra (Abbott, Mississauga, Ontario, Canada) is an electronic BHBA hand-held meter that has excellent accuracy (Iwersen et al., 2009). However, one of the main drawbacks of the Precision Xtra technology is the additional farm labor resources required to systematically test all animals at risk for hyperketonemia. Implementing a hyperketonemia surveillance program using DHI monthly milk test data could be a more practical and less labor-intensive approach. Flow-injection analysis (Gustafsson and Emanuelsson, 1996) and Fourier transform infrared (FTIR) spectroscopy (Heuer et al., 2001; van Knegsel et al., 2010; van der Drift et al., 2012) are laboratory techniques that have been developed for use with DHI milk testing to measure concentrations of BHBA, acetone, fat, and protein in milk. Interestingly, flow-injection analysis is generally used to calibrate FTIR spectroscopy for BHBA and ac- 
etone measurement (de Roos et al., 2007). However, the ability of milk ketone bodies values from flow-injection analysis to accurately diagnose hyperketonemia, as compared with whole blood or serum BHBA, has not been evaluated.

Therefore, the first objective of this study was to determine the correlations between blood BHBA and milk components measured by flow-injection analysis (BHBA and acetone) and FTIR (fat and protein). The second objective was to establish threshold values for these milk components to predict hyperketonemia in dairy cows.

\section{MATERIALS AND METHODS}

\section{Experimental Design}

This cross-sectional study was conducted from June to September 2010. Holstein dairy cows $(\mathrm{n}=200)$ from client herds of the Ruminant Field Service at the Université de Montréal (Saint-Hyacinthe, Québec, Canada) were enrolled in the study. A convenience sample of 37 herds, located within a $25-\mathrm{km}$ radius around the veterinary college, were selected for participation in this study. Sample-size calculations were performed (PASS 11, NCSS Statistical Software, Kaysville, UT) based on the following assumptions: correlation coefficients between 0 and 0.3 or between 0.70 and 1 , a rho value of 0.05 to adjust for herd clustering, and power of $80 \%$. All procedures were approved by the Animal Care Committee (10-Rech-1556) of the Université de Montréal.

Participating herds were visited once by a research technician within $4 \mathrm{~h}$ of milk sampling on the monthly DHI herd test day (Valacta, Sainte-Anne-de-Bellevue, Québec, Canada). During these farm visits, the 5 cows that had most recently calved and that were greater than 2 and less than 90 DIM were enrolled on the study and blood sampled. A 1-mL whole blood sample was drawn from the coccygeal vessels of each enrolled cow and immediately analyzed for BHBA concentration using the Precison Xtra meter. On the herd test day, DHI technicians were responsible for collecting individual composite milk samples from each enrolled cow using the approved metering device (International Committee on Animal Recording). Milk samples were preserved using bronopol tablets (Brotab, Systems Plus, Baden, ON, Canada), transported overnight on ice, and then analyzed at the DHI laboratory (Valacta). All DHI milk samples were analyzed for ketone bodies (BHBA and acetone) with a continuous flow analyzer $\left(\mathrm{San}^{++}\right.$, Skalar, Breda, the Netherlands) using the procedure described by de Roos et al. (2007). Milk BHBA and acetone values were calculated based on a standard subtraction method for the continuous flow analyzer, which may lead to small negative numbers. These negative numbers suggest very low concentrations of BHBA and acetone. Milk samples were also analyzed for fat and CP using FTIR (MilkoScan FT+, FOSS, Hillerod, Denmark).

\section{Statistical Analyses}

Data were entered into a Microsoft Excel spreadsheet (Microsoft Corp., Redmond, WA). All statistical analyses were performed using SAS (version 9.3, SAS Institute Inc., Cary, NC). A variable titled fat-to-protein $(\mathbf{F}: \mathbf{P})$ ratio was created by dividing the fat value by the $\mathrm{CP}$ value for each sample. The F:P ratio was considered a milk component. The MEANS procedure was used to generate descriptive statistics for the blood BHBA and milk component data. The FREQ procedure was used to calculate the true prevalence (based on blood BHBA) and apparent prevalence (based on milk components) of hyperketonemia.

Correlation Between Blood BHBA and Milk Components. The CORR procedure was used to calculate Pearson correlation coefficients for blood BHBA and individual milk components.

Optimal Thresholds for Milk Components to Predict Hyperketonemia. The MIXED procedure was used to construct generalized linear mixed models to examine the univariable relationship between blood BHBA concentration (continuous variable) and each individual milk component (continuous variables), while controlling for the random effect of herd. Any variable with a $P$-value $<0.05$ in the univariable models was used to build receiver operating characteristic curves to illustrate graphically the ability of each milk component to correctly classify cows as hyperketonemia positive (defined as blood BHBA $\geq 1.4 \mathrm{mmol} / \mathrm{L}$ ) or negative (defined as blood BHBA $<1.4 \mathrm{mmol} / \mathrm{L}$ ).

The LOGISTIC procedure was used to calculate the area under the curve (AUC) for each milk component. The AUC represents the probability of a randomly selected cow with hyperketonemia having a positive milk test result for BHBA, acetone, fat, protein, or F:P compared with a randomly selected cow without hyperketonemia (Dohoo et al., 2003). The Wald chi-squared contrast test was used to compare differences in AUC. An optimal threshold for predicting hyperketonemia was established for each milk component as the value that yielded the maximum sum of sensitivity (Se) and specificity (Sp). These optimal thresholds were used to determine the positive predictive value (PPV) and negative predictive value (NPV) for each milk component compared with blood BHBA values. Cohen's kappa (Dohoo et al., 2003) was used to evaluate the 


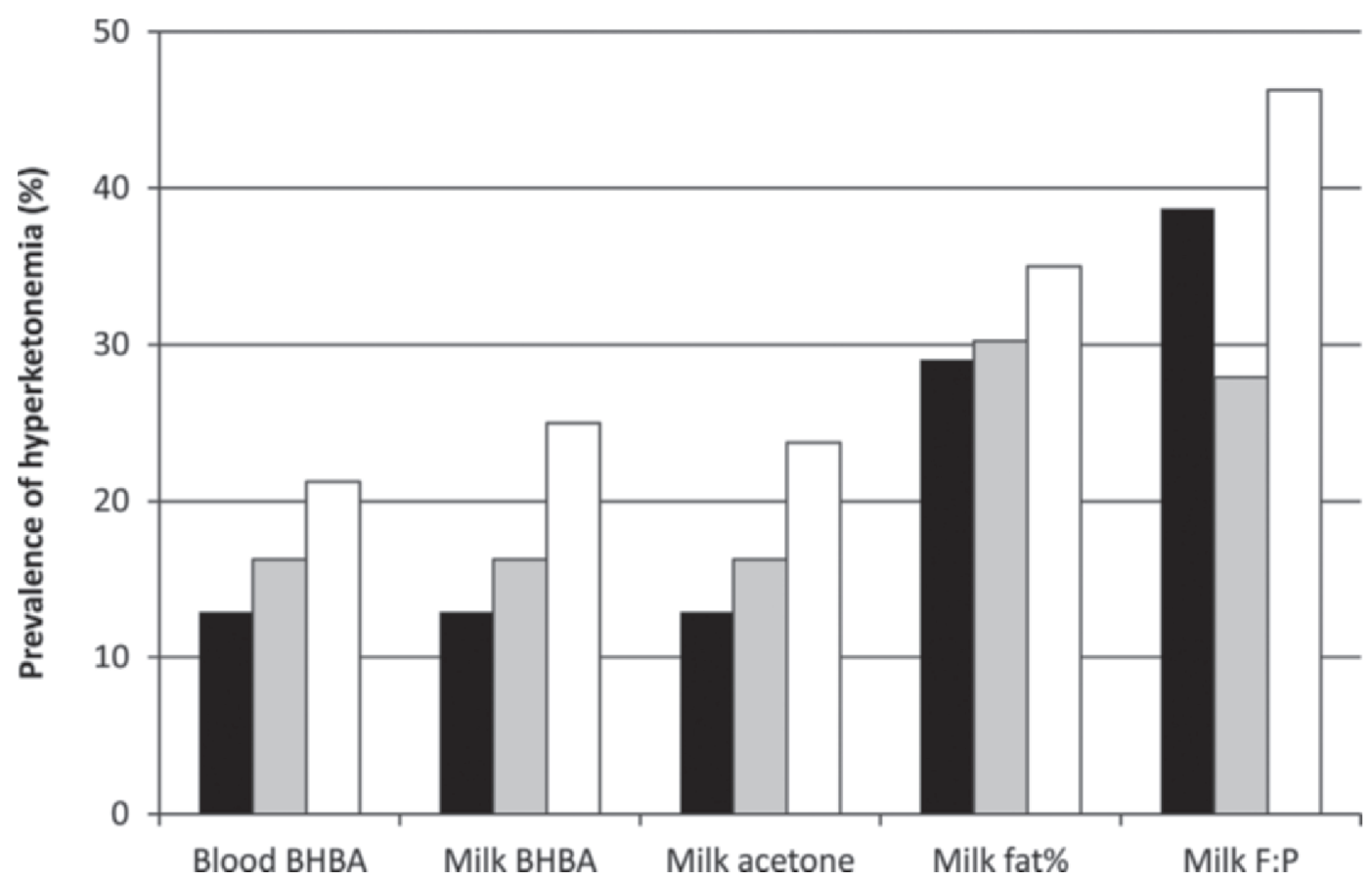

Figure 1. Apparent prevalence of hyperketonemia by parity group $(1=$ black, $2=$ gray, and $3+=$ white $)$ as diagnosed using blood BHBA $(\geq 1.4 \mathrm{mmol} / \mathrm{L})$, milk BHBA $(\geq 0.20 \mathrm{mmol} / \mathrm{L})$, milk acetone $(\geq 0.08 \mathrm{mmol} / \mathrm{L})$, milk fat percentage $(\geq 4.2 \%)$, and milk fat-to-protein ratio (F:P; $\geq 1.3)$ in 163 Holstein dairy cows from 37 herds.

agreement between the test results for blood BHBA and milk components (BHBA, acetone, fat, protein, F:P ratio).

Series and parallel testing (Dohoo et al., 2003) were used to examine how combining multiple test results affected the AUC, Se, Sp, PPV, and NPV. A cow was classified as positive using series testing if all test results were positive; anything else was negative. A cow was classified as positive using parallel testing if at least one test result was positive; anything else was negative.

The LOGISTIC procedure was used to construct a multivariable logistic regression model to evaluate the relationship between blood BHBA and milk components (BHBA, acetone, fat, protein, and F:P ratio). A backward elimination process was used to reduce the full model one variable at the time, based on a level of significance of $P<0.05$. The final model was used to calculate AUC, Se, Sp, PPV, NPV, and kappa.

\section{RESULTS}

A total of 200 Holstein cows were enrolled and sampled in this study. However, 37 cows from 18 herds had incomplete milk-analysis data and were excluded. Therefore, a total of 163 cows from 37 herds were used for statistical analyses. Cow parity was distributed as follows: parity $1=20.1 \%$, parity $2=27.9 \%$, and parity $3+=52.0 \%$. Blood and milk samples were collected from the cows at an average of 25.5 DIM ( SD = 17.1; median $=22.0 ;$ range $=2$ to 89 ). Table 1 presents the descriptive statistics for blood BHBA and milk component values. Negative values for milk BHBA ( $\mathrm{n}=$ $1,0.6 \%)$ and acetone $(\mathrm{n}=12,7.4 \%)$ were retained in the analyses because they are representative of very low concentrations. The overall true prevalence of hyperketonemia was $21.0 \%$, based on blood BHBA $\geq 1.4$ $\mathrm{mmol} / \mathrm{L}$. The apparent prevalence of hyperketonemia, as diagnosed by each individual milk component, stratified by cow parity group is shown in Figure 1.

Pearson correlation coefficients between blood BHBA and milk components were as follows: BHBA $=0.89(P<0.01)$, acetone $=0.73(P<0.01)$, fat $=$ $0.21(P<0.01)$, protein $=0.04(P=0.59)$, and $\mathrm{F}: \mathrm{P}$ ratio $=0.17(P=0.03)$. Results of the univariable

Table 1. Descriptive statistics for blood BHBA and milk components [BHBA, acetone, fat, protein, and fat-to-protein ratio $(\mathrm{F}: \mathrm{P})]$ values found in 163 lactating Holstein dairy cows from 37 herds

\begin{tabular}{lcccc}
\hline Item & Mean & SD & Median & Range \\
\hline Blood BHBA (mmol/L) & 1.14 & 0.99 & 0.8 & 0.2 to 6.3 \\
Milk & & & & \\
BHBA (mmol/L) & 0.18 & 0.17 & 0.13 & -0.03 to 1.09 \\
Acetone (mmol/L) & 0.10 & 0.29 & 0.03 & -0.03 to 2.63 \\
Fat (\%) & 4.10 & 1.36 & 3.80 & 2.07 to 11.86 \\
Protein (\%) & 3.08 & 0.43 & 2.98 & 2.32 to 4.43 \\
F:P & 1.34 & 0.45 & 1.22 & 0.66 to 4.58 \\
\hline
\end{tabular}


Table 2. Results of generalized linear mixed models, accounting for herd as a random effect, for predicting blood BHBA with individual milk values of BHBA, acetone, fat, protein, and fat-to-protein ratio (F:P) in 163 lactating Holstein dairy cows from 37 herds

\begin{tabular}{lccccccc}
\hline & \multicolumn{3}{c}{ Intercept } & & \multicolumn{3}{c}{ Slope } \\
\cline { 2 - 3 } \cline { 6 - 8 } Model & $\beta_{0}$ & $\mathrm{SE}$ & $P$-value & & $\beta_{1}$ & SE & $P$-value \\
\hline BHBA $(\mathrm{mmol} / \mathrm{L})$ & 0.012 & 0.010 & 0.342 & & 0.150 & 0.006 & $<0.001$ \\
Acetone $(\mathrm{mmol} / \mathrm{L})$ & -0.13 & 0.02 & $<0.001$ & & 0.202 & 0.015 & $<0.001$ \\
Fat $(\%)$ & 3.75 & 0.18 & $<0.001$ & & 0.318 & 0.113 & 0.006 \\
Protein $(\%)$ & 3.04 & 0.06 & $<0.001$ & & 0.035 & 0.035 & 0.323 \\
F:P & 1.25 & 0.06 & $<0.001$ & & 0.085 & 0.038 & 0.026 \\
\hline
\end{tabular}

analyses between blood BHBA and each individual milk component are shown in Table 2. Receiver operating characteristic curves and AUC for milk BHBA, acetone, fat, and F:P ratio are presented in Figure 2. Optimal threshold values to predict hyperketonemia, based on the highest sum of sensitivity and specificity, were milk $\mathrm{BHBA} \geq 0.20 \mathrm{mmol} / \mathrm{L}$, acetone $\geq 0.08$ $\mathrm{mmol} / \mathrm{L}$, fat $\geq 4.2 \%$, and $\mathrm{F}: \mathrm{P}$ ratio $\geq 1.3$. The AUC, Se, Sp, PPV, NPV, and kappa values for series and parallel testing, and the final multivariable model are shown in Table 3.

\section{DISCUSSION}

To the best of the authors' knowledge, this is the first study to compare milk concentrations of BHBA and acetone determined by continuous injection-flow analysis with blood BHBA from Precision Xtra or laboratory testing. Correlations between blood BHBA and milk ketone bodies (BHBA and acetone) indicate that these measures were strongly correlated (Dohoo et al., 2003).

Several test characteristics were evaluated in this study to assess the ability of milk components to ac-

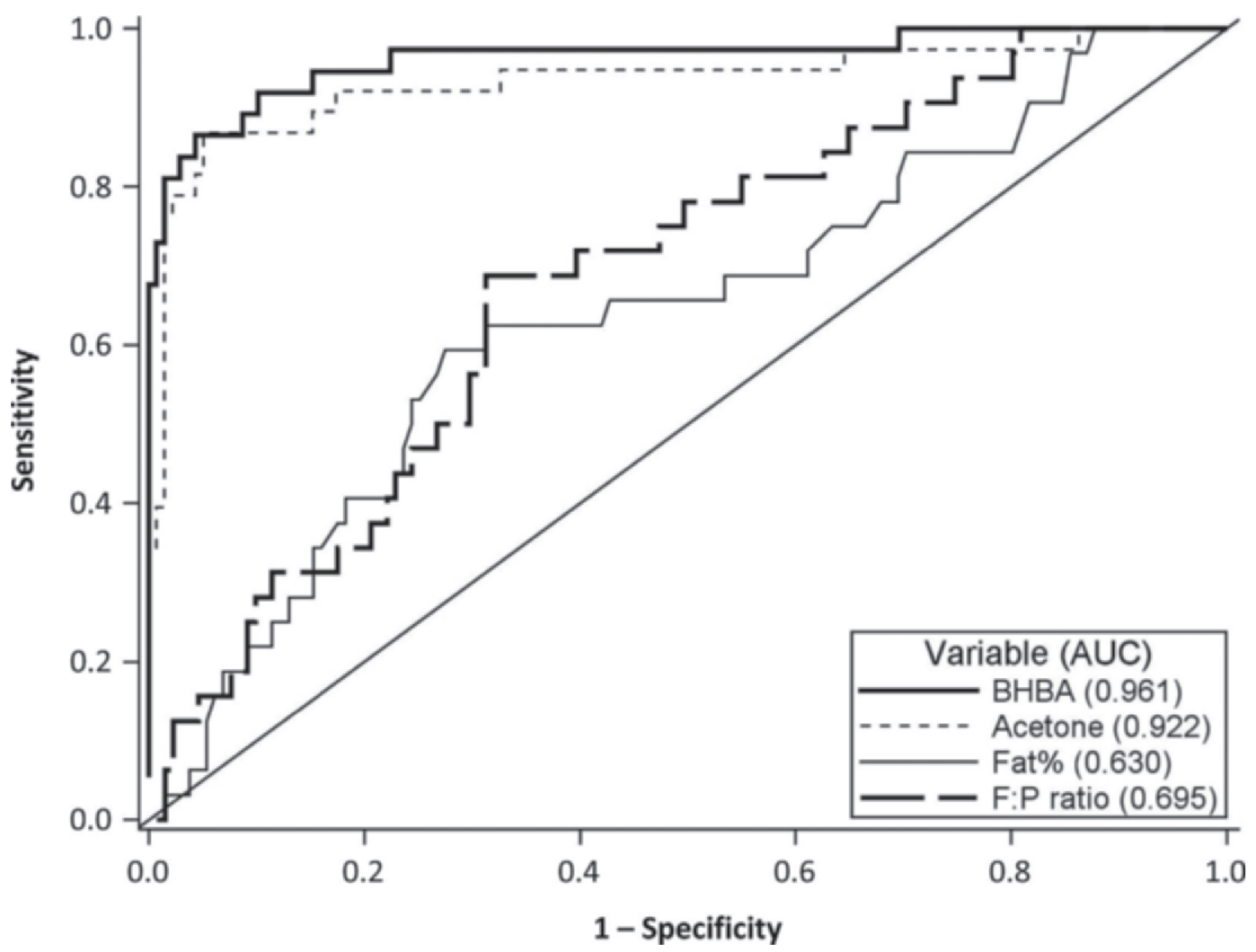

Figure 2. Receiver operating characteristic curves with their respective area under the curve (AUC) for milk BHBA, acetone, fat, and fatto-protein ratio (F:P) using various threshold values to predict hyperketonemia (blood BHBA $\geq 1.4$ mmol/L) in 163 lactating Holstein dairy cows from 37 herds. 
Table 3. Area under the curve (AUC), sensitivity (Se), specificity (Sp), positive predictive value (PPV), negative predictive value (NPV), and Cohen's kappa $(\kappa)$ of milk BHBA, acetone, fat, and fat-to-protein ratio (F:P) tested individually; of milk BHBA, acetone, fat, and F:P tested using series and parallel interpretation; and of a multivariable model to predict hyperketonemia (blood BHBA $\geq 1.4 \mathrm{mmol} / \mathrm{L} ;$ prevalence of $21 \%$ ) in 163 lactating Holstein dairy cows from 37 herds

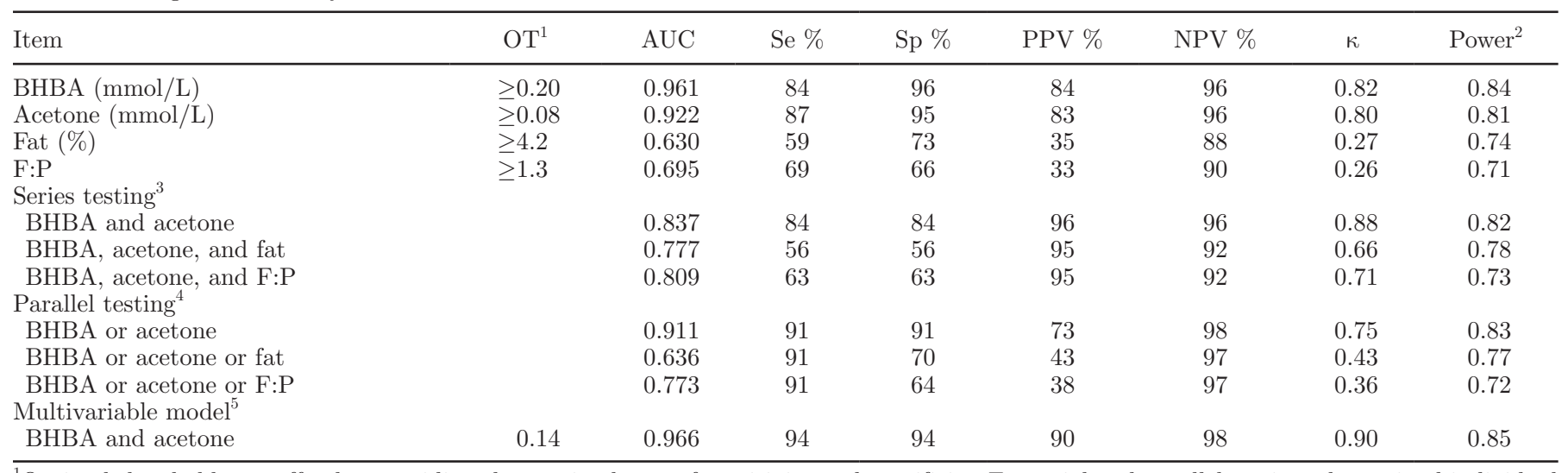

${ }^{1}$ Optimal threshold: cut-off value providing the maximal sum of sensitivity and specificity. For serial and parallel testing, the optimal individual threshold for each variable was used.

${ }^{2}$ Statistical power of the model.

${ }^{3}$ Series testing: a cow was considered positive if all tests were positive; anything else was negative.

${ }^{4}$ Parallel testing: a cow was considered positive if at least one test was positive; to be considered negative, all tests used had to be negative.

${ }^{5}$ Multivariable logistic regression.

curately predict hyperketonemia. The accuracy of using milk BHBA and milk acetone concentrations to predict hyperketonemia in dairy cows was assessed using receiver operating characteristic curves, and both of these milk components had very high AUC (greater than 90\%). Similarly, the comparison of blood BHBA and milk ketone concentrations revealed very strong agreement. Results from previous studies that used FTIR to quantify milk ketone bodies and then compared with those results to blood BHBA (threshold of $1,200 \mu \mathrm{mol} / \mathrm{L}$ ) found slightly lower AUC, ranging from 82 to $85 \%$ (van Knegsel et al., 2010; van der Drift et al., 2012). In the current study, the optimal thresholds for milk BHBA and acetone were both individually accurate, with Se greater than $80 \%$ and Sp greater than $95 \%$. These measures of accuracy tend to vary between studies because of the different methods used for defining optimal threshold values. In the present study, the value that provided the maximal sum of sensitivity and specificity was selected as the optimal threshold. However, other methods have been reported in the literature, such as the maximum proportion of observed agreement of correct test results (van Knegsel et al., 2010 ) or targeting a sensitivity of at least 90\% (Enjalbert et al., 2001). In the end, these different methods may produce different optimal threshold levels because they are not aiming for the same goal. Another possible reason for the differences in thresholds reported here versus other studies could be that hyperketonemia was defined using a slightly higher critical value $(\geq 1.4$ vs. $\geq 1.2 \mathrm{mmol} / \mathrm{L}$; Enjalbert et al., 2001; van Knegsel et al., 2010; van der Drift et al., 2012). The primary reason for selecting $\geq 1.4 \mathrm{mmol} / \mathrm{L}$ as the blood BHBA threshold in the present study was that this was the same value used to validate Precision Xtra for measuring blood BHBA (Iwersen et al., 2009). It is important to keep in mind, however, that even though Precision Xtra has excellent accuracy, it is not the gold standard test for hyperketonemia (Iwersen et al., 2009). Thus, some cows in the current study may have been incorrectly classified for hypoketonemia based on the Precision Xtra results than if laboratory testing of blood or serum BHBA were used.

The use of series testing for milk BHBA, acetone, fat, and $F: P$ values greatly increased the Sp for predicting hyperketonemia, whereas parallel testing increased the Se. These results were expected because it is widely recognized that series testing will increase specificity, and parallel testing generally increases sensitivity (Dohoo et al., 2003). The AUC for series and parallel testing, however, was not greater than when using milk BHBA alone. This implies that series or parallel testing for predicting hyperketonemia was not more accurate than using milk BHBA results alone. Series testing of BHBA and acetone improved the PPV compared with using them individually. Therefore, although the overall accuracy of prediction for series testing was not greater (similar AUC), a better PPV may support the use of series testing over individual testing when the prevalence of hyperketonemia is similar to the present study $(21 \%)$. Combining multiple test results in series or parallel interpretation may be useful when consid- 
ering on-farm hyperketonemia testing strategies. For example, producers may choose to employ a parallel testing strategy for hyperketonemia because the firstline treatment of oral propylene glycol administration is a relatively safe and inexpensive intervention. However, producers are highly encouraged to consult with their nutritionists and veterinarians before a sampling and testing program for hyperketonemia is implemented on the farm.

The final multivariable model showed that considering both milk BHBA and acetone values simultaneously led to a greater AUC for predicting hyperketonemia. This result was also supported by greater kappa, $\mathrm{Se}$, and Sp values. Thus, the diagnostic accuracy for hyperketonemia can be improved by considering both milk BHBA and acetone values together. The use of such a multivariable model could be done by DHI organizations and be reported to producers with monthly reports. Although the outputs from this model have little practical meaning for producers, the use of this model to define hyperketonemia based on the established threshold from the current study could be useful and practical.

Milk ketone concentrations from DHI testing could potentially be used to diagnose hyperketonemia in individual cows. However, DHI herd testing is generally completed on a monthly basis, which may not be frequent enough for this to be the only diagnostic test for hyperketonemia used on dairy farms. It is likely that in order for DHI testing to be effective at the cow level to diagnose hyperketonemia, multiple DHI tests would have to be completed each month. The economics of this approach would need to be formally evaluated and compared with other individual cow diagnostic testing strategies.

Information on milk fat, protein, and the F:P ratio are readily available to producers because they are commonly reported values in DHI herd-analysis reports. However, even though they were statistically significant in univariable analyses, fat and the $\mathrm{F}: \mathrm{P}$ ratio were poor predictors of hyperketonemia (Dohoo et al., 2003). The AUC for milk fat and the F:P ratio were considerably lower than that of the milk ketone bodies, which is consistent with findings from previous studies (Duffield et al., 1997; van Knegsel et al., 2010). Moreover, based on the optimal threshold values, the Se and Sp for these milk components were notably lower than the milk ketone bodies and did not exceed $75 \%$. The optimal threshold for F:P ratio in this study was the same as that reported by Duffield et al. (1997) but slightly lower than that of van Knegsel et al. (2010). Overall, regardless of which threshold was used, the performance of milk fat and the F:P ratio for predicting hyperketonemia remained poor. The weak performance of milk fat and protein concentrations compared with blood BHBA may be attributed to the influence of environmental (Soberon et al., 2011; Loker et al., 2012), genetic (Loor, 2010; Loker et al., 2012), and nutritional factors, such as effective fiber, carbohydrate source and degradability, the use of monensin, or protein sources (Wattiaux and Karg, 2004; Charbonneau et al., 2006; Duffield et al., 2008). Incorporating values of fat or F:P ratio into a series or parallel testing strategy with milk BHBA and acetone test results was not beneficial. Therefore, these results suggest that the use of milk fat and the F:P ratio has limited value to diagnose hyperketonemia in dairy cows.

This study was conducted using cows sampled between 2 and 90 DIM. The prevalence of hyperketonemia is generally higher earlier in lactation (McArt et al., 2012). Hence, it is unclear at this time whether sampling cows only during the high risk period for hyperketonemia (between 2 and 14 DIM for example) would have provided different results. It is possible that different optimal thresholds would have been obtained if the study population targeted only cows in early lactation. Further research needs to be conducted to investigate this point.

Milk ketone concentrations from samples collected as part of routine DHI testing might be able to be used for systematic herd surveillance of hyperketonemia. It is well recognized that hyperketonemia is a condition that provides important information on the health status of dairy herds. Therefore, with the development and validation of diagnostic tests that are accurate, practical, and economical, producers should be encouraged to establish long-term systematic surveillance programs that will help with the early detection of transition-cow health problems, such as hyperketonemia. However, some limitations exist with DHI ketone testing programs, including infrequent sampling (generally on a monthly basis) and the lag time between milk sampling and receiving the test results. These limitations suggest that DHI testing should be used as a herd-level tool to monitor hyperketonemia, rather than to diagnose individual cows. Further work is needed to investigate appropriate herd-level surveillance strategies using DHI test results on ketone bodies.

\section{CONCLUSIONS}

Milk BHBA and acetone values from flow-injection analysis had excellent correlation with blood BHBA values. The use of flow-injection analysis to quantify milk BHBA $(\geq 0.20 \mathrm{mmol} / \mathrm{L})$ and acetone $(\geq 0.08 \mathrm{mmol} / \mathrm{L})$ alone, or in combination, had excellent accuracy to detect hyperketonemia in dairy cows. Accuracy was slightly improved using series and parallel testing of 
milk BHBA and acetone. Based on these findings, it is concluded that flow-injection-analysis test results could potentially be used in herd-level surveillance programs for hyperketonemia. Further work is needed to investigate appropriate herd-level surveillance strategies using DHI test results on ketone bodies.

\section{ACKNOWLEDGMENTS}

This project was financially supported by Valacta and by the "Fonds de recherche clinique Pfizer de la Clinique ambulatoire de la Faculté de médecine vétérinaire" of the Université de Montréal. Technical support provided by Geneviève Forté and Véronique Fauteux is greatly appreciated. Appreciation is also extended to Rachid Kouaouci and Christa Deacon for milk ketones analysis and Valacta field technicians for sample collection. The authors acknowledge the participating dairy farmers for their time and willingness to participate in this study and Cindy Todd for reviewing this manuscript and providing helpful comments to improve it.

\section{REFERENCES}

Andersson, L., and U. Emanuelsson. 1985. An epidemiological study of hyperketonemia in Swedish dairy cows; Determinants and the relation to fertility. Prev. Vet. Med. 3:449-462.

Charbonneau, E., P. Y. Chouinard, G. Allard, H. Lapierre, and D. Pellerin. 2006. Milk from forage as affected by carbohydrate source and degradability with alfalfa silage-based diets. J. Dairy Sci. $89: 283-293$.

de Roos, A. P., H. J. van den Bijgaart, J. Horlyk, and G. de Jong. 2007. Screening for subclinical ketosis in dairy cattle by Fourier transform infrared spectrometry. J. Dairy Sci. 90:1761-1766.

Dohoo, I., W. Martin, and H. Stryhn. 2003. Veterinary Epidemiologic Research. 1st ed. AVC Inc., Charlottetown, PE.

Duffield, T., D. Kelton, K. Lissemore, and J. Lumsden. 1997. Use of test day milk fat and milk protein to detect subclinical ketosis in dairy cattle in Ontario. Can. Vet. J. 38:713-718.

Duffield, T. F., K. D. Lissemore, B. W. McBride, and K. E. Leslie 2009. Impact of hyperketonemia in early lactation dairy cows on health and production. J. Dairy Sci. 92:571-580.

Duffield, T. F., A. R. Rabiee, and I. J. Lean. 2008. A meta-analysis of the impact of monensin in lactating dairy cattle. Part 2. Production effects. J. Dairy Sci. 91:1347-1360.
Duffield, T. F., D. Sandals, K. E. Leslie, K. Lissemore, B. W. McBride, J. H. Lumsden, P. Dick, and R. Bagg. 1998. Efficacy of monensin for the prevention of subclinical ketosis in lactating dairy cows. J. Dairy Sci. 81:2866-2873.

Enjalbert, F., M. C. Nicot, C. Bayourthe, and R. Moncoulon. 2001. Ketone bodies in milk and blood of dairy cows: Relationship between concentrations and utilization for detection of subclinical ketosis. J. Dairy Sci. 84:583-589.

Gustafsson, A. H., and U. Emanuelsson. 1996. Milk acetone concentration as an indicator of hyperketonemia in dairy cows: The critical value revised. Anim. Sci. 63:183-188.

Heuer, C., H. J. Luinge, E. T. G. Lutz, Y. H. Schukken, J. H. van der Maas, H. Wilmink, and J. P. T. M. Noordhuizen. 2001. Determination of acetone in cow milk by Fourier transform infrared spectroscopy for the detection of subclinical ketosis. J. Dairy Sci. $84: 575-582$.

Iwersen, M., U. Falkenberg, R. Voigtsberger, D. Forderung, and W. Heuwieser. 2009. Evaluation of an electronic cowside test to detect subclinical ketosis in dairy cows. J. Dairy Sci. 92:2618-2624.

LeBlanc, S. J., K. E. Leslie, and T. F. Duffield. 2005. Metabolic predictors of displaced abomasum in dairy cattle. J. Dairy Sci. $88: 159-170$.

Loker, S., C. Bastin, F. Miglior, A. Sewalem, L. R. Schaeffer, J. Jamrozik, A. Ali, and V. Osborne. 2012. Genetic and environmental relationships between body condition score and milk production traits in Canadian Holsteins. J. Dairy Sci. 95:410-419.

Loor, J. J. 2010. Genomics of metabolic adaptations in the peripartal cow. Animal: Int. J. Anim. Biosci. 4:1110-1139.

McArt, J. A. A., D. V. Nydam, and G. R. Oetzel. 2012. Epidemiology of subclinical ketosis in early lactation dairy cattle. J. Dairy Sci 95:5056-5066.

Ospina, P. A., D. V. Nydam, T. Stokol, and T. R. Overton. 2010. Associations of elevated nonesterified fatty acids and $\beta$-hydroxybutyrate concentrations with early lactation reproductive performance and milk production in transition dairy cattle in the northeastern United States. J. Dairy Sci. 93:1596-1603.

Soberon, F., C. M. Ryan, D. V. Nydam, D. M. Galton, and T. R. Overton. 2011. The effects of increased milking frequency during early lactation on milk yield and milk composition on commercial dairy farms. J. Dairy Sci. 94:4398-4405.

van der Drift, S. G. A., R. Jorritsma, J. T. Schonewille, H. M. Knijn, and J. A. Stegeman. 2012. Routine detection of hyperketonemia in dairy cows using Fourier transform infrared spectroscopy analysis of $\beta$-hydroxybutyrate and acetone in milk in combination with test-day information. J. Dairy Sci. 95:4886-4898.

van Knegsel, A. T. M., S. G. A. van der Drift, M. Horneman, A. P. W. de Roos, B. Kemp, and E. A. M. Graat. 2010. Short communication: Ketone body concentration in milk determined by Fourier transform infrared spectroscopy: Value for the detection of hyperketonemia in dairy cows. J. Dairy Sci. 93:3065-3069.

Wattiaux, M. A., and K. L. Karg. 2004. Protein level for alfalfa and corn silage-based diets: I. Lactational response and milk urea nitrogen. J. Dairy Sci. 87:3480-3491. 